OPEN ACCESS

Edited by:

Franc Llorens,

Center for Biomedical Research on Neurodegenerative Diseases

(CIBERNED), Spain

Reviewed by: Dennis Qing Wang, Southern Medical University, China Davide Chiasserini

University of Perugia, Italy

*Correspondence: Touqeer Ahmed touqeer.aahmed@gmail.com; touqeer.ahmed@asab.nust.edu.pk

Received: 16 March 2020 Accepted: 22 June 2020 Published: 22 July 2020

Citation: Iqbal G, Braidy N and Ahmed T (2020) Blood-Based Biomarkers for Predictive Diagnosis of Cognitive Impairment in a Pakistani Population. Front. Aging Neurosci. 12:223. doi: 10.3389/fnagi.2020.00223

\section{Blood-Based Biomarkers for Predictive Diagnosis of Cognitive Impairment in a Pakistani Population}

\author{
Ghazala Iqbal ${ }^{1}$, Nady Braidy ${ }^{2}$ and Touqeer Ahmed ${ }^{1 *}$ \\ ${ }^{1}$ Neurobiology Laboratory, Department of Healthcare Biotechnology, Atta-ur-Rahman School of Applied Biosciences, \\ National University of Sciences \& Technology (NUST), Islamabad, Pakistan, ${ }^{2}$ Centre for Healthy Ageing, School of Psychiatry, \\ Faculty of Medicine, University of New South Wales, Sydney, NSW, Australia
}

Numerous studies have identified an association between age-related cognitive impairment $(\mathrm{Cl})$ and oxidative damage, accumulation of metals, amyloid levels, tau, and deranged lipid profile. There is a concerted effort to establish the reliability of these blood-based biomarkers for predictive diagnosis of $\mathrm{Cl}$ and its progression. We assessed the serum levels of high-density lipoprotein (HDL) cholesterol, low-density lipoprotein (LDL) cholesterol, triglycerides, total cholesterol, selected metals (Cu, Al, Zn, $\mathrm{Pb}, \mathrm{Mn}, \mathrm{Cad})$, and total-tau and amyloid beta-42 protein in mild $(n=71)$, moderate $(n=86)$ and severe $(n=25)$ cognitively impaired patients and compared them with age-matched healthy controls $(n=90)$ from Pakistan. We found that a decrease in HDL cholesterol (correlation coefficient $r=0.467)$ and amyloid beta-42 $(r=0.451)$ were associated with increased severity of $\mathrm{Cl}$. On the other hand, an increase in cholesterol ratio $(r=-0.562)$, LDL cholesterol $(r=-0.428)$, triglycerides, and total-tau $(r=-0.443)$ were associated with increased severity of $\mathrm{Cl}$. Increases in cholesterol ratio showed the strongest association and correlated with increases in tau concentration $(r=0.368)$, and increased triglycerides were associated with decreased amyloid beta-42 ( $r=-0.345)$. Increased $\mathrm{Cu}$ levels showed the strongest association with tau increase and increased $\mathrm{Zn}$ and $\mathrm{Pb}$ levels showed the strongest association with reduced amyloid beta- 42 levels. Receiver Operating Characteristic (ROC) showed the cutoff values of blood metals ( $\mathrm{Al}$, $\mathrm{Pb}, \mathrm{Cu}, \mathrm{Cad}, \mathrm{Zn}$, and $\mathrm{Mn}$ ), total-tau, and amyloid beta-42 with sensitivity and specificity. Our data show for the first time that blood lipids, metals (particularly $\mathrm{Cu}, \mathrm{Zn}, \mathrm{Pb}$, and $\mathrm{Al}$ ), serum amyloid-beta-42/tau proteins modulate each other's levels and can be collectively used as a predictive marker for $\mathrm{Cl}$.

Keywords: biomarkers, oxidative stress, cognitive impairment, amyloid-beta, serum, tau, metals, lipids

\section{INTRODUCTION}

Cognitive impairment (CI) is characterized by short and long term memory loss, deterioration of language, inability to execute motor functions, and/or poor recognition of objects, and impairments in executive abilities (American Psychiatric Association, 1996). Timely diagnosis of CI in old age is very important because CI is likely to progress to the development of dementias (Ritchie et al., 2014, 2017; Tang et al., 2020). Improved diagnoses of CI can help in better management of 
the disease and might delay dementias in these subjects. CI is the major component of the aging process and is associated with a variety of risk factors, such as smoking, high drug, and alcohol consumption, fewer years of formal education, low-income status, various metabolic diseases like hypertension and diabetes (Freedman et al., 2001; Raz and Rodrigue, 2006), elevated levels of metals (Iqbal et al., 2018), brain shrinkage with age (Raz et al., 2004), genetic factors such as APOE copies (Deary et al., 2009) and oxidative stress (Raz and Daugherty, 2018; Gandhi and Abramov, 2012).

Reliable biomarkers for prediction of early CI are needed, although there has been little success in this aspect. Here, we investigated the role of blood-based lipids, amyloid beta-42, tau and metals, and their correlations as potential biomarkers for improved diagnosis of CI. Lipids play an important role in neurodegeneration by promoting oxidative stress and influencing amyloid plaques formation, thus playing a contributory role in CI (Bodovitz and Klein, 1996; Xicoy et al., 2019). Higher blood cholesterol level leads to lipid peroxidation and reduced levels of several antioxidant enzymes (including superoxide dismutase) have been reported (Sparks et al., 1994). Lipids have also been recently used to distinguish between elderly subjects with small vessel disease and "healthy" age-matched controls (Liu et al., 2020). The association of low-density lipoprotein (LDL) cholesterol, high-density lipoprotein (HDL) cholesterol and total cholesterol with cognitive function has been previously reported but remains inconclusive (Postiglione et al., 1989; Wieringa et al., 1997) due to limited availability of data and varied techniques of assessment of lipid profiles (Anstey et al., 2008; Segatto et al., 2014; Zanchetti et al., 2014). It has also been well established that redox-active metals can disturb the equilibrium between free radical generation and antioxidant potential of cells by increasing the levels of reactive oxygen species (Singh et al., 2019).

Amyloid beta-42 as a biomarker in cerebrospinal fluid (CSF) and/or plasma has been extensively studied in Alzheimer's disease (AD; Vos et al., 2013) and other neurocognitive disorders (Ritchie et al., 2014, 2017). Amyloid beta-42 is a proteolytic fragment of amyloid precursor protein (APP), which is selectively cleaved by beta and gamma-secretase enzymes to yield the toxic amyloid beta-42 peptide (Selkoe, 1994) and its fibrils damage synapses (Chen et al., 2017) and causes oxidative stress (Ferrera et al., 2008). There is contradictory evidence on whether the levels of amyloid-beta in the CSF and/or plasma are clinically relevant biomarkers in $\mathrm{AD}$, since published results are difficult to interpret, and there are variations in study design and methodologies used. For instance, some studies have reported increased levels of amyloid-beta (Vos et al., 2013; Petersen and O'Bryant, 2019; Tang et al., 2020) while others have reported lower levels (Song et al., 2011; Ruiz et al., 2013; Mizoi et al., 2014). However, both of these above-mentioned types of studies concluded that amyloid-beta cannot be an accurate biomarker, suggesting that levels of amyloid beta are certainly modulated by other factors (possibly metals, lipids, and tau) and further studies are required.

Tau proteins are abundant in the central nervous system (CNS) and are mainly active in the distal portion of axons hence stabilizing microtubules (Billingsley and Kincaid, 1997). As compared to the amyloid-beta, tau seems to be a reliable marker. Several studies have reported that elevated levels of total-tau and phosphorylated tau in the CSF correlate well with CI and progressing to dementias (Hansson et al., 2006; Diniz et al., 2008; Mattsson et al., 2009; Monge-Argilés et al., 2010; Olsson et al., 2016). As CI is associated with several neurological disorders establishing selective and specific blood-based biomarkers is challenging (Grundke-Iqbal et al., 1986).

Blood-based biomarkers for CI offer ease of access, and in some cases, plasma markers (plasma tau for $\mathrm{AD}$ particularly) show better correlation (Zetterberg et al., 2013). CSF based biomarkers can be reliable, however, CSF acquisition is invasive and difficult to obtain, and sometimes data has to be supported by neuro-imaging scans (Jia et al., 2019), which are expensive and time-consuming (Mapstone et al., 2014). A large amount of CSF is absorbed in the blood, suggesting that proteins present in the serum have the potential to act as biomarkers in the neurodegenerative diseases. Therefore, proteins associated with the axonal injury and damage of the blood-brain barrier may be measured in the serum (Zetterberg et al., 2013). Keeping in view all these factors, we studied selected plasma/sera biomarkers for CI in Pakistani health. The key goal of this study was to observe the association between total and fractional cholesterol with the extent of CI and its correlation with amyloid beta-42 and total tau. Furthermore, we estimated the association between serum total-tau and amyloid beta- 42 with various metals in the blood and the stages of cognitively impaired subjects and compared the data with age matched healthy controls. Finally receiver operating characteristic (ROC) analysis was performed to evaluate the specificity and sensitivity of amyloid beta-42, tau protein, and various metals as potential biomarkers for diagnosis of mild, moderate, and severe CI.

\section{MATERIALS AND METHODS}

\section{Ethics}

This study protocol was approved by the Internal Review Board (IRB) of the Atta-ur-Rahman School of Applied Biosciences, National University of Sciences and Technology (approval letter number 35IRB). The procedures were performed following the code of ethics of the World Medical Association (Declaration of Helsinki). Written informed consent was obtained from all subjects and/or caregivers included in the study.

\section{Subjects}

A total of 273 subjects aged more than 50 years were included in this study. A well-defined inclusion criterion was practiced. Subjects having proper evidence of the CI as reported by neuro physicians or psychiatrists and with more than 50 years of age were included. The patients under any kind of therapies (including the lipid-lowering medications) were excluded from the study. Detailed information was obtained from all subjects through an approved questionnaire. The questionnaire includes the date of birth, occupation, medical history, medications, and 


\section{Subjects more than $\mathbf{5 0}$ years of age}

Exclusion Criteria

1) Age less than 50 years

2) Known genetic neurologic disorder or history of psychiatric illness.

3) Kidney or liver failure

4) Cardiovascular disease or Diabetes mellitus

5)Blood transmitted infections,

6) Tumors/cancers
Inclusion Criteria

1) Objective evidence (from physical and neurological examination and laboratory tests usually MMSE) of cognitive impairment.

2) Either gender

3) Irrespective of race and origin

\section{$\downarrow$}

Presence of a disorder in cognitive function for most of the time for at least two weeks. Reported by the individual or a reliable informer
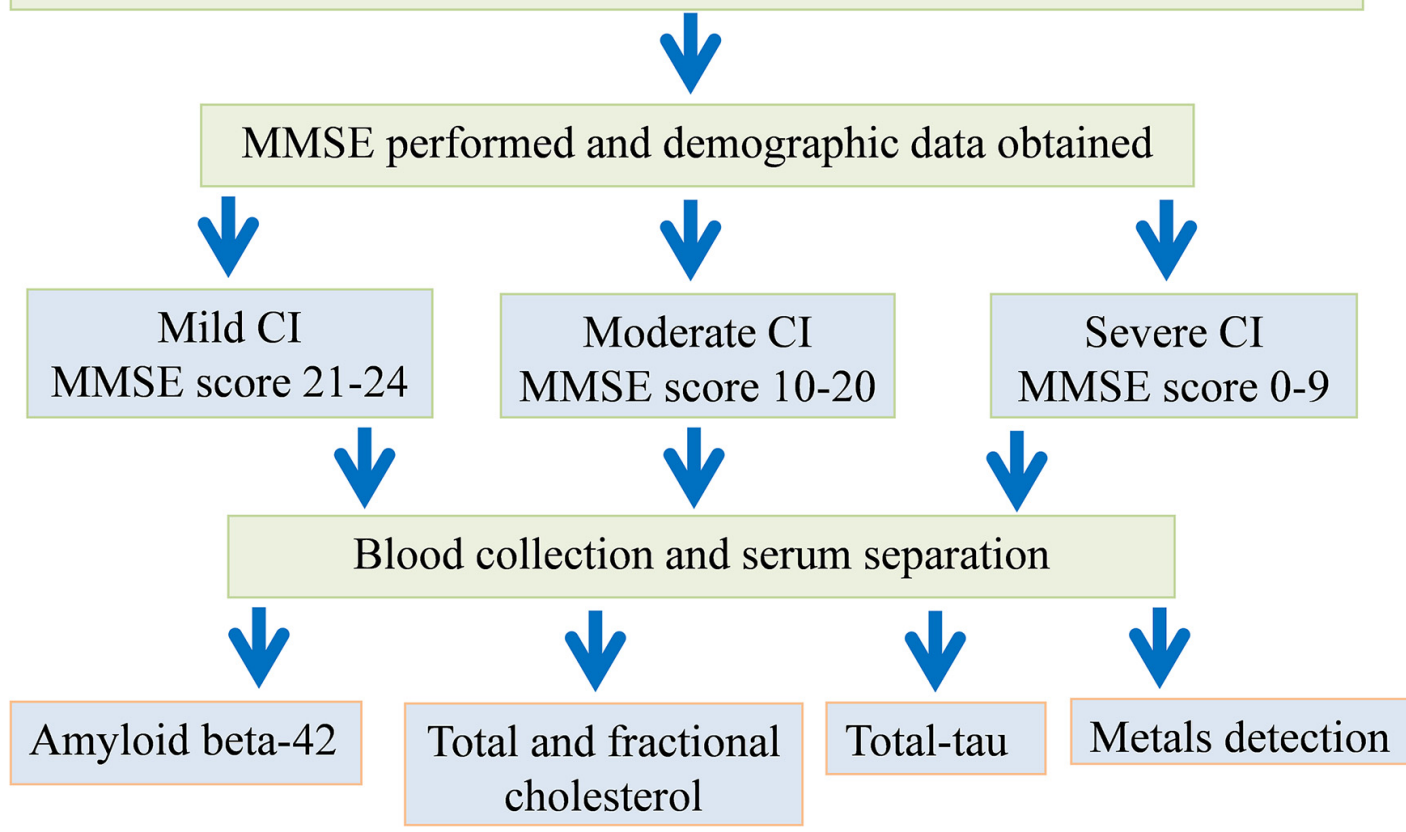

FIGURE 1 | Flow diagram of study design and patients exclusion criteria. MMSE, mini-mental state examination; Cl, cognitive impairment.

lifestyle of the subjects. The study design and the patient's exclusion criteria are shown in Figure 1.

\section{Cognitive Function Assessment and Classification of Subjects}

Screening of cognitive function was performed using a standard and widely used and accepted 30 point questionnaire test known as the Folstein test or mini-mental state examination (MMSE; Folstein et al., 1975; Ferrante et al., 2019; Nardes et al., 2020). The MMSE was administered by an independent health care provider to evaluate overall cognitive function. The subjects were classified based on MMSE score into mild, moderate, and severe CI (Table 1). In this study of 273 subjects, 72 patients with mild CI, 86 with moderate CI, 25 with severe CI and 90 age-matched healthy control were examined for lipids profiling, total-tau and amyloid beta- 42 in serum and correlation of these biomarkers with metals ( $\mathrm{Al}, \mathrm{Pb}, \mathrm{Zn}, \mathrm{Cu}, \mathrm{Cd}$, and $\mathrm{Mn}$ ) concentrations were studied. Metals levels in these subjects are reported earlier (Iqbal et al., 2018). All cognitively impaired subjects with co-morbidities were excluded from the study. Older "healthy" individuals aged 50 years, with overall good health and with normal MMSE score were used as age-matched healthy controls in this study. 
TABLE 1 | Demographic data of the study subjects.

\begin{tabular}{|c|c|c|c|c|c|}
\hline \multicolumn{2}{|c|}{ Variables/parameters measured } & \multirow{2}{*}{$\begin{array}{c}\text { Age matched healthy } \\
\text { control }(\boldsymbol{n}=90)\end{array}$} & \multirow{2}{*}{$\begin{array}{c}\begin{array}{c}\text { Mild cognitive } \\
\text { impairment }(\boldsymbol{n}=\mathbf{7 1})\end{array} \\
22.7 \pm 1\end{array}$} & \multirow{2}{*}{$\begin{array}{c}\text { Moderate cognitive } \\
\text { impairment }(\boldsymbol{n}=\mathbf{8 6})\end{array}$} & \multirow{2}{*}{$\begin{array}{c}\begin{array}{c}\text { Severe cognitive } \\
\text { impairment }(\boldsymbol{n}=\mathbf{2 5})\end{array} \\
5.96 \pm 2\end{array}$} \\
\hline MMSE score & & & & & \\
\hline \multirow[t]{2}{*}{ Gender } & Male & 48 & 33 & 51 & 10 \\
\hline & Female & 42 & 39 & 35 & 15 \\
\hline Age years (SD) & & $58.1 \pm 6.6$ & $61.7 \pm 9$ & $65.1 \pm 10.9$ & $79.68 \pm 7$ \\
\hline Weight kg (SD) & & $73.07 \pm 7.5$ & $71.25 \pm 7.2$ & $72.2 \pm 7$ & $74.7 \pm 5.1$ \\
\hline \multirow[t]{2}{*}{ Living standard } & Rural & 76 & 59 & 74 & 18 \\
\hline & Urban & 14 & 12 & 12 & 7 \\
\hline \multirow[t]{4}{*}{ Education } & Primary (0-5 yeras) & 26 & 34 & 43 & 17 \\
\hline & Secondary level & 49 & 32 & 39 & 8 \\
\hline & Higher secondary level & 3 & 3 & 3 & 0 \\
\hline & Bachelors and above & 12 & 2 & 1 & 0 \\
\hline \multirow[t]{2}{*}{ Marital status } & Married & 86 & 64 & 74 & 19 \\
\hline & Unmarried & 4 & 8 & 12 & 6 \\
\hline \multirow[t]{2}{*}{ Smoking } & Smokers & 11 & 21 & 39 & 10 \\
\hline & No smokers & 89 & 50 & 47 & 15 \\
\hline
\end{tabular}

\section{Serum Collection}

All the procedure was performed under aseptic conditions. Five milliliters of blood was collected by vein puncture from each subject using a sterile needle. Two milliliters was transferred to EDTA vacutainer tubes for metal detection while three milliliters of blood in the other vacutainer was left to clot at room temperature for about $20 \mathrm{~min}$. After that, vacutainers were centrifuged at 3,000 rpm for $10 \mathrm{~min}$ to separate the serum from clotted blood. This serum was then immediately transferred to labeled Eppendorf tubes and stored at $-80^{\circ} \mathrm{C}$ for further use.

\section{Lipid Profile Measurements}

Triglycerides, HDL cholesterol, and total cholesterol were measured from serum by Merck Microlab 300 apparatus. Triglycerides were measured by the Abcam triglyceride kit (Catalogue Number: ab65336), total cholesterol was estimated by Merck kit (Catalogue Number: 428901) and cholesterol was calculated by Abcam human ELISA kit (Catalogue number: ab12561). All procedures were carried out according to the manufacturer's instructions. LDL cholesterol was estimated using the Friedenwald equation i.e.,

$$
\begin{aligned}
\mathrm{LDL} \text { cholesterol }= & \text { total cholesterol } \\
& - \text { HDL cholesterol }-(\text { triglycerides } / 2.2)
\end{aligned}
$$

Cholesterol ratio was calculated by the formula

$$
\text { Cholesterol ratio }=\text { Total cholesterol/HDL cholesterol }
$$

\section{Total-Tau Level Measurement}

Serum Total-tau was estimated using the human tau ELISA kit (catalog number ab210972 and lot: GR302657-1) purchased from Abcam, Cambridge, UK. All the procedures were performed according to the manufacturer's instructions.

\section{Amyloid Beta-42 Level Measurement}

Measurement of serum amyloid beta- 42 was carried out using human amyloid beta-42 ELISA kit (E-El-H0543; lot: AK0017JAN11029) purchased from Elabscience (Hubei, China). The assay was performed according to the manufacturer's instructions.

\section{Quantification of Metal Levels and Their ROC Analyses}

Blood was digested by a microwave-assisted acid digestion method as previously described (Iqbal et al., 2018). Heavy metals were analyzed in digested blood samples by double-beam Perkin Elmer atomic absorption spectrometer model 700 (Perkin Elmer, USA). Metals levels are reported earlier (Iqbal et al., 2018) and their ROC was analyzed here to find out their diagnostic significance.

\section{Statistical Analysis}

The data were statistically analyzed using GraphPad prism software and variables were compared using one-way ANOVA followed by Bonferroni post hoc test. Data were expressed as mean \pm standard error of the mean (SEM) and considered significant only if the $p$-value was less than 0.05 . Correlation analysis among the two variables was calculated using Pearson's correlation by GraphPad prism. ROC analyses were carried out to find the cutoff concentration of total-tau, amyloid beta- $42, \mathrm{Cu}$, $\mathrm{Al}, \mathrm{Zn}, \mathrm{Pb}, \mathrm{Mn}$, and $\mathrm{Cd}$.

\section{RESULTS}

\section{Demographic Data of Subjects}

The demographic data obtained from all subject groups i.e., age-matched healthy control, mild CI, moderate CI, and severe CI patients are summarized in Table 1 . There were more females compared to the number of males in diseased groups. Most of the subjects were from urban areas. There was less number of individuals with higher education in the case of moderate and severe CI groups. An increasing trend in percent of smokers from mild to severe cognitively impaired groups was observed.

\section{Lipid Profile Measurement in Blood Samples of CI Subjects}

The LDL cholesterol concentrations in mild CI $(100.5 \pm 3.67 \mathrm{mg} / \mathrm{dl})$, moderate CI $(107.8 \pm 3.01 \mathrm{mg} / \mathrm{dl})$ and severe CI groups $(125.8 \pm 5.22 \mathrm{mg} / \mathrm{dl})$ were significantly 
A Concentration of LDL cholesterol in serum samples

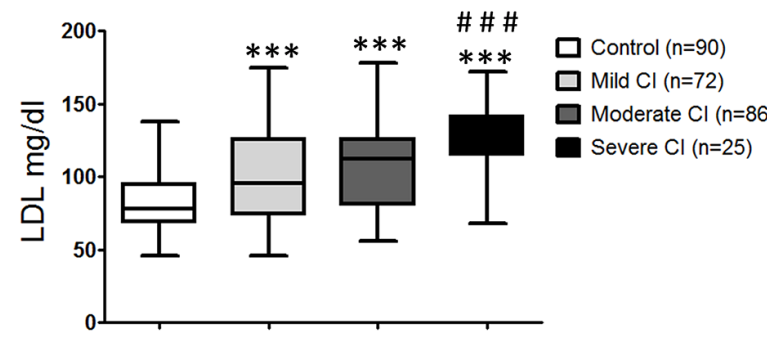

B Concentration of HDL cholesterol in serum samples

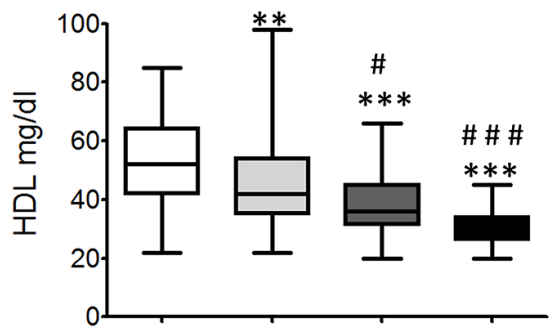

C Concentration of triglycerides in serum samples

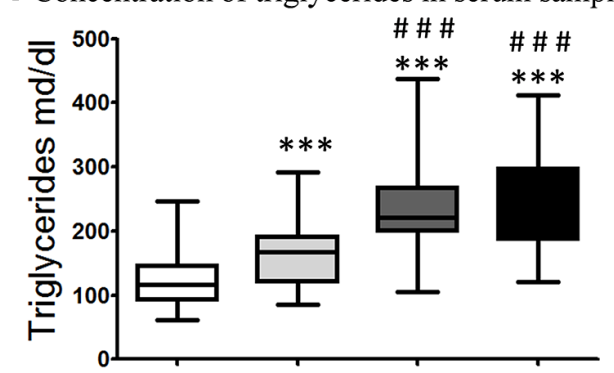

D Concentration of cholesterol in serum samples

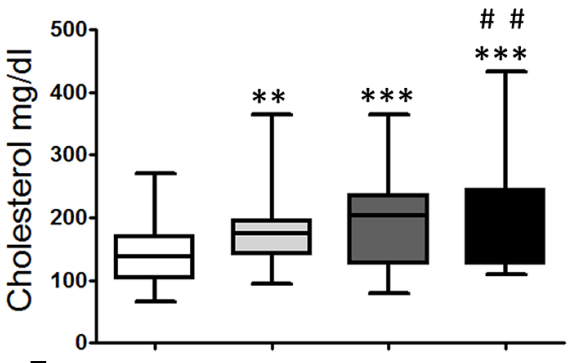

E Cholesterol ratio in serum samples

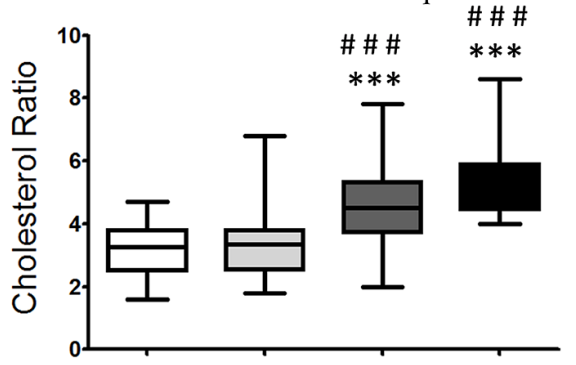

FIGURE 2 | Bar graph showing the total and fractional cholesterol in serum samples of age-matched healthy control, mild $\mathrm{Cl}$, moderate $\mathrm{Cl}$ and severe cognitively impaired subjects. (A) Low-density lipoprotein (LDL) cholesterol in serum samples. (B) High-density lipoprotein (HDL) cholesterol level in serum samples.

(C) Triglycerides level in serum samples. (D) Total cholesterol concentration in serum samples. (E) Cholesterol ratio in serum samples. ${ }^{* *} p<0.01$,

${ }^{* * *} p<0.001$ compared with age-matched healthy control group; ${ }^{\#} p<0.05,{ }^{\# \#} p<0.01$, ${ }^{\# \# \#} p<0.001$ comparison with mild cognitive impaired group; $\mathrm{n}$, samples size.

$\left({ }^{* * *} p<0.001\right)$ higher than the age matched healthy control group (Figure 2A). The level of HDL cholesterol in serum samples of age matched healthy controls $(51.9 \pm 1.41 \mathrm{mg} / \mathrm{dl})$ were significantly higher than mild $\left(44.56 \pm 1.67 \mathrm{mg} / \mathrm{dl}\right.$; $\left.{ }^{* *} p<0.01\right)$, moderate $(38.26 \pm 1.31 \mathrm{mg} / \mathrm{dl}$; $\left.{ }^{* * *} p<0.001\right)$ and severe $\left(30.68 \pm 1.28 \mathrm{mg} / \mathrm{dl}\right.$; $\left.{ }^{* * *} p<0.001\right)$ cognitively impaired subjects (Figure 2B). It was found that triglycerides levels in serum were significantly higher in mild CI $\left(161.5 \pm 5.65 \mathrm{mg} / \mathrm{dl} ;{ }^{* *} p<0.01\right)$, moderate CI $\left(230.3 \pm 8.1 \mathrm{mg} / \mathrm{dl} ;{ }^{* * *} p<0.001\right)$ and severe CI groups $\left(248.5 \pm 15 \mathrm{mg} / \mathrm{dl} ;{ }^{* * *} p<0.001\right)$ comparative to age matched healthy controls $(30.68 \pm 1.28 \mathrm{mg} / \mathrm{dl}$; Figure $2 \mathrm{C})$. The total cholesterol levels were significantly lower in age matched healthy control group $(138.9 \pm 4.49 \mathrm{mg} / \mathrm{dl})$ compared to those diagnosed with mild CI $(172.5 \pm 5.79 \mathrm{mg} / \mathrm{dl} ; * * * p<0.01)$, moderate CI $\left(195.8 \pm 6.73 \mathrm{mg} / \mathrm{dl} ;{ }^{* * *} p<0.001\right)$ and severe CI $\left(217.1 \pm 17.48 \mathrm{mg} / \mathrm{dl} ;{ }^{* * *} p<0.001\right)$. However there was no significant difference observed among mild CI and moderate CI group and also among moderate
CI and severe CI groups (Figure 2D). Cholesterol ratio was significant $\left({ }^{* * *} p<0.001\right)$ increased in subjects diagnosed with moderate CI (4.51 $\pm 0.13 \mathrm{mg} / \mathrm{dl})$ and severe CI $(5.28 \pm 0.24 \mathrm{mg} / \mathrm{dl})$ when compared to age matched healthy controls. Moreover there was no significant difference among subjects with mild CI (3.43 $\pm 0.13 \mathrm{mg} / \mathrm{dl})$ and age matched healthy controls (Figure 2E).

\section{Correlation Between Lipids Profile and MMSE}

Correlation analysis was performed in order to observe the association of concentrations of LDL cholesterol, HDL cholesterol, triglycerides, total cholesterol and cholesterol ratio with the extent of CI. Correlation test revealed that the strongest negative correlation was observed with cholesterol ratio $\left(r=-0.562 ;{ }^{* * *} p<0.001\right)$ followed by LDL cholesterol $\left(r=-0.428 ;{ }^{* * *} p<0.001\right)$, total cholesterol $(r=-0.39$; $\left.{ }^{* * *} p<0.001\right)$ and triglycerides $\left(r=-0.329\right.$; $\left.{ }^{* * *} p<0.001\right)$, respectively (Figures $3 \mathrm{~A}-\mathrm{E}$ ). A strong positive correlation 
A Correlation of LDL cholesterol with MMSE score

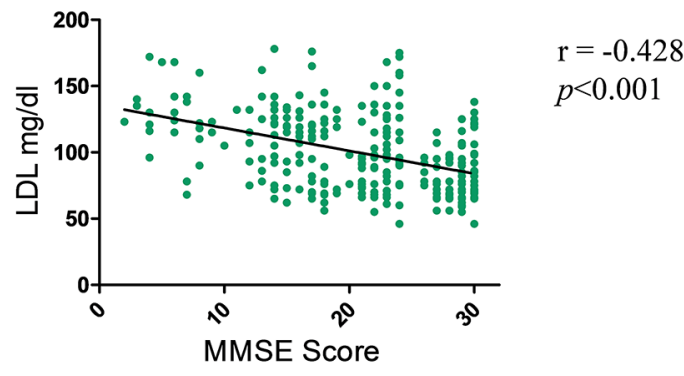

B Correlation of HDL cholesterol with MMSE score

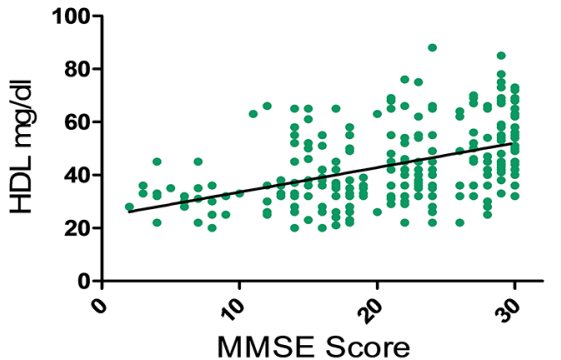

$\mathbf{r}=0.467$

$p<0.001$

C Correlation of Triglycerides with MMSE score

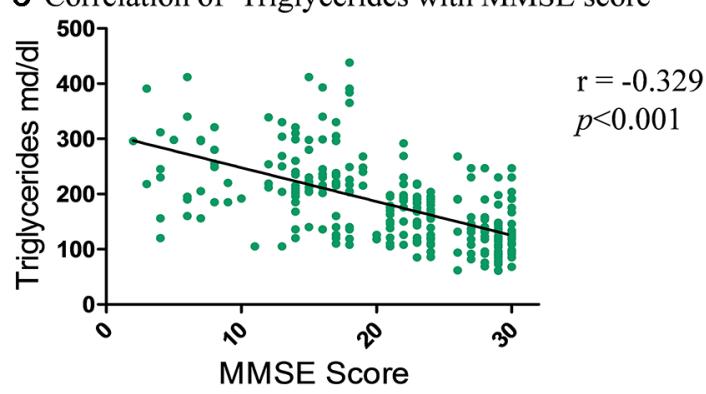

D Correlation of total cholesterol with MMSE score

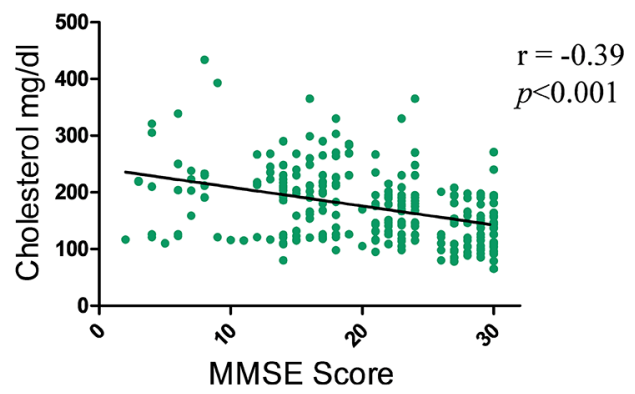

E Correlation of cholesterol ratio with MMSE score

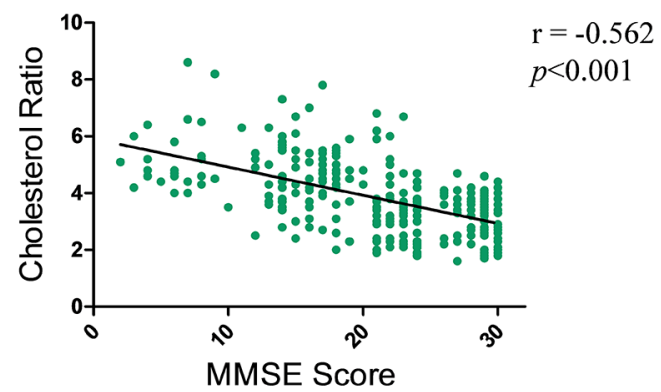

FIGURE 3 | Correlation graph showing the relationship between the total and fractional cholesterol in serum samples and subjects MMSE score. (A) Correlation of LDL cholesterol with MMSE scores. (B) Correlation of HDL cholesterol with MMSE scores. (C) Correlation of triglycerides with MMSE scores. (D) Correlation of total cholesterol with MMSE scores. (E) Correlation of cholesterol ratio with MMSE scores.

was observed with HDL cholesterol concentration $(r=0.467$; *** $p<0.001)$ and MMSE score.

\section{Tau Levels in Serum, ROCs in CI Severity and Its Correlation With MMSE, Lipids Profile, and Metals Levels}

The concentration of serum total-tau levels increased with increasing severity of CI (Figure 4A). The total-tau concentration in subjects with severe CI $(50.05 \pm 3.68 \mathrm{pg} / \mathrm{ml}$; $\left.{ }^{* *} p<0.01\right)$ and moderate CI $\left(44.94 \pm 3.19 \mathrm{pg} / \mathrm{ml} ;{ }^{*} p<0.05\right)$ were significantly higher than the age-matched healthy control $(31.8 \pm 2.79 \mathrm{pg} / \mathrm{ml})$. There were significantly low levels of tau in subjects with mild CI $\left(34.4 \pm 3.76 \mathrm{pg} / \mathrm{ml} ;{ }^{* *} p<0.01\right)$ in comparison to severe CI group. No significant difference was observed among mild CI group and age-matched healthy control (Figure 4A). A significant and downhill linear correlation was found between total-tau levels and MMSE score $(r=-0.443$; ${ }^{* * *} p<0.001$; Figure 4B).
ROC analysis revealed that tau levels showed the best results in moderate CI followed by severe CI, but not very accurate in mild CI (Supplementary Figure S1). In the case of moderate CI vs. control, the AUC for tau was 0.80 and the cutoff value was $47.37 \mathrm{pg} / \mathrm{ml}$; with a sensitivity of $55 \%$ and specificity of $90 \%$ to detect moderate CI patients (Figure 4C). While, in case of severe CI vs. control, the AUC was 0.75 , the cutoff concentration was $46.79 \mathrm{pg} / \mathrm{ml}$; with a sensitivity of $50 \%$ and specificity of $90 \%$ to detect severe CI (Figure 4D).

Correlation analysis of tau concentration and cholesterol fractions showed the strongest positive correlation with cholesterol ratio $\left(r=0.368 ;{ }^{* * *} p<0.001\right)$ followed by triglyceride $\left(r=0.32{ }^{* *} p<0.01\right)$ and least with LDL cholesterol $(r=-0.251$; ${ }^{\star} p<0.05$; Figures 5A-C). A negative correlation between the HDL cholesterol $\left(r=-0.245 ;{ }^{*} p<0.05\right)$ and tau concentration whereas no correlation with total cholesterol was shown (Supplementary Figures S2A,B).

Metal concentrations were correlated with tau levels to determine any association among the elevated levels of metals 
A Concentration of total tau in serum samples

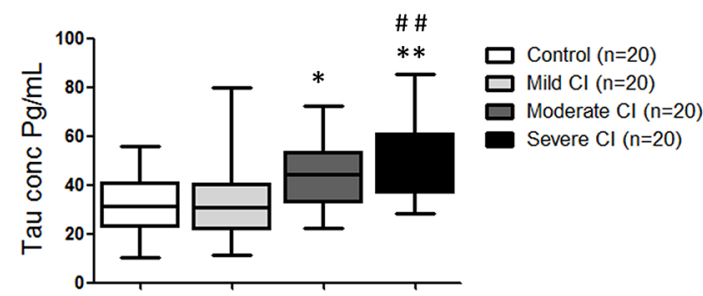

B Correlation of tau concentration with MMSE score

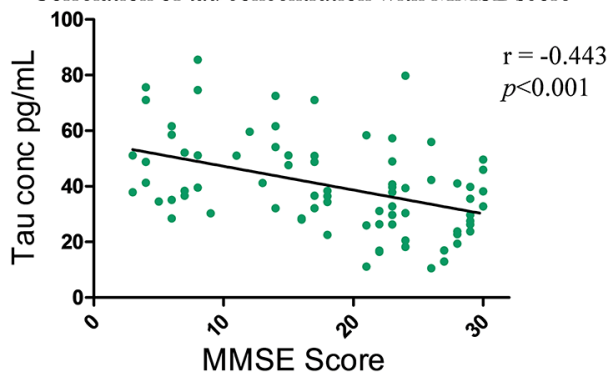

C ROC analysis for tau; control vs moderate CI

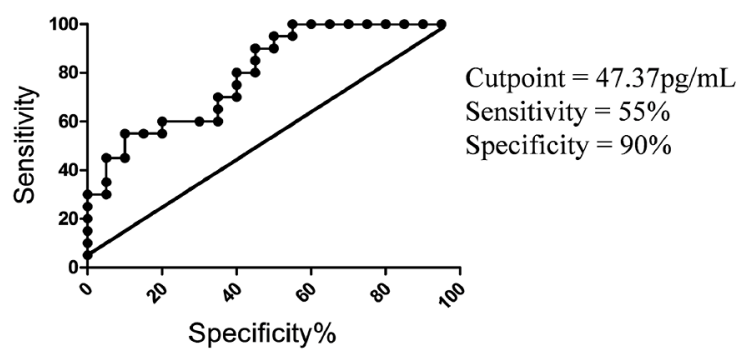

D ROC analysis for tau; control vs severe CI

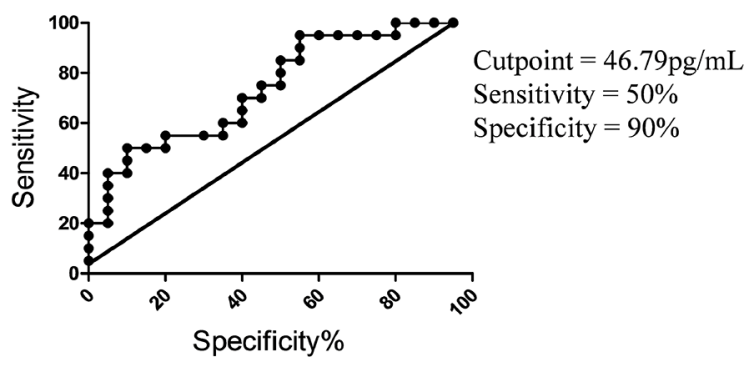

FIGURE 4 | Serum tau levels and its correlation with MMSE and Receiver Operating Characteristic (ROC) curves. (A) Concentration of total-tau in serum samples in studied subjects. ${ }^{*} p<0.05,{ }^{* \star} p<0.01$ compared with age-matched healthy control group; ${ }^{\# \#} p<0.01$ comparison with mild cognitive impaired group; $n=$ sample size. (B) Correlation of tau concentration with MMSE scores. ROC analysis of serum tau proteins between (C) Control vs. moderate $\mathrm{Cl}$ and (D) Control vs. severe Cl groups.

with the levels of serum tau proteins. Pearson's correlation demonstrated significant correlation of tau with $\mathrm{Cu}(r=0.32$; $\left.{ }^{* *} p<0.01\right)$, followed by $\mathrm{Zn}\left(r=0.28\right.$; $\left.{ }^{*} p<0.05\right), \mathrm{Al}(r=0.26$; $\left.{ }^{*} p<0.05\right)$ as shown in Figures 5D-F. While $\mathrm{Mn}(r=0.23$; $\left.{ }^{*} p<0.05\right)$ was weakly correlated and $\mathrm{Pb}(r=-0.251 ; \mathrm{ns})$ and $\mathrm{Cd}(r=-0.251$; ns) were non-significant (Supplementary Figures S2C-E).

\section{Amyloid Beta-42 Levels in Serum, ROCs in CI Severity and Its Correlation With MMSE, Lipids Profile and Metals Levels}

The amyloid beta-42 levels declined with the increase in CI (Figure 6A). The amyloid beta- 42 concentration was low in subjects diagnosed with severe CI $(17.05 \pm 1.68 \mathrm{pg} / \mathrm{ml})$ compared to mild CI $\left(23.52 \pm 1.36 ;{ }^{* *} p<0.01 \mathrm{pg} / \mathrm{ml}\right)$ and age matched healthy controls $\left(24.68 \pm 1.68 \mathrm{pg} / \mathrm{ml} ;{ }^{* * *} p<0.001\right)$. Correlation analyses revealed significant positive correlation of amyloid beta-42 levels and MMSE score $\left(r=0.451 ;{ }^{* * *} p<0.001\right.$; Figure 6B).

ROC analyses revealed that amyloid beta-42 did now show promising results for mild CI vs. control (Supplementary Figure S3). In case of moderate CI vs. control, the AUC was 0.74 , the cutoff value was $22.68 \mathrm{pg} / \mathrm{ml}$; with sensitivity $80 \%$ and specificity $70 \%$ (Figure 6C). While in case of severe CI vs. control, the AUC was 0.79 , the cutoff value of amyloid beta- 42 was $22.57 \mathrm{pg} / \mathrm{ml}$; with a sensitivity of $90 \%$ and specificity of $70 \%$ to detect severe cognitively impaired patients (Figure 6D).

Furthermore amyloid beta- 42 correlation with cholesterol fractions was evaluated and a negative correlation was seen in the order of triglyceride $\left(r=-0.345 ;{ }^{* *} p<0.01\right)$, LDL cholesterol $\left(r=-0.34 ;{ }^{* *} p<0.01\right)$ and cholesterol ratio $\left(r=-0.323{ }^{* *} p<0.01\right.$; Figures 7A-C). A positive correlation with HDL cholesterol $\left(r=0.292\right.$; $\left.^{* *} p<0.01\right)$ and amyloid beta-42 concentration, whereas weak negative correlation of total cholesterol $\left(r=-0.28 ;{ }^{\star} p<0.05\right)$ with amyloid beta- 42 was seen (Supplementary Figures S4A,B).

When amyloid beta- 42 concentration was correlated with metals, it was found that amyloid beta- 42 is negatively correlated with the concentration of $\mathrm{Zn}\left(r=-0.32\right.$; $\left.{ }^{* *} p<0.01\right)$, followed by $\mathrm{Pb}\left(r=-0.31\right.$; $\left.^{* *} p<0.01\right)$ and $\mathrm{Cu}\left(r=-0.26\right.$; $\left.^{* *} p<0.01\right)$ as shown in Figures 7D-F. Al was marginally negatively associated $\left(r=-0.25 ;{ }^{*} p<0.05\right)$ whereas $\mathrm{Mn}(r=-0.21$; ns) and Cd ( $r=-0.20$; ns) showed non-significant correlation (Supplementary Figures S4C-E).

\section{ROC Analysis of Metals to Detect Mild Cl, Moderate $\mathrm{Cl}$ and Severe $\mathrm{Cl}$}

Metals levels were estimated in these subjects (Iqbal et al., 2018) and their ROC analyses for diagnostic value were evaluated here. It was found that $\mathrm{Cu}$ showed the best diagnostic value (Figures $\mathbf{8 A}-\mathrm{C}$ ), followed by $\mathrm{Zn}$ (Figures $8 \mathrm{D}-\mathrm{F}$ ), $\mathrm{Al}$ (Figures 8G-I), and $\mathrm{Pb}$ (Figures 8J-L). ROC analyses of $\mathrm{Mn}$ and Cd were also analyzed (Supplementary Figures S5A-F).

Finally, we added amyloid beta-42 and total tau concentration and ROC analysis was performed. The results did not show very promising ROC values of these combined biomarkers (Supplementary Figure S6). 
ACorrelation of cholesterol ratio with tau

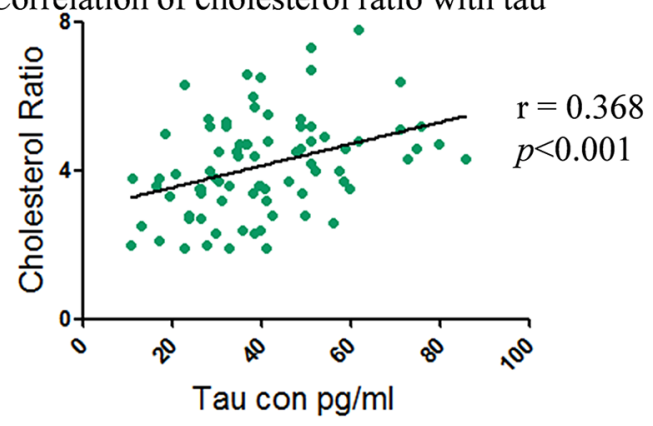

B Correlation of Triglycerides with tau

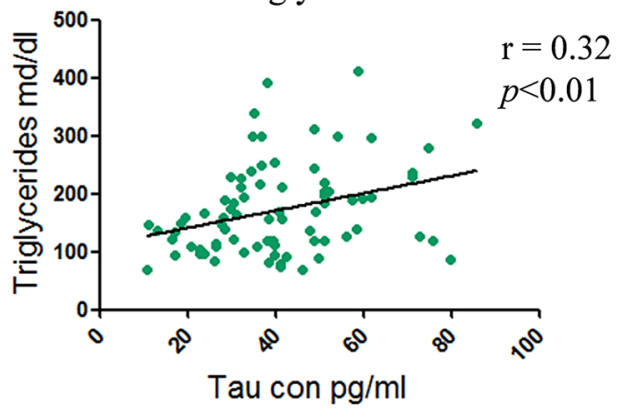

C Correlation of LDL cholesterol with tau

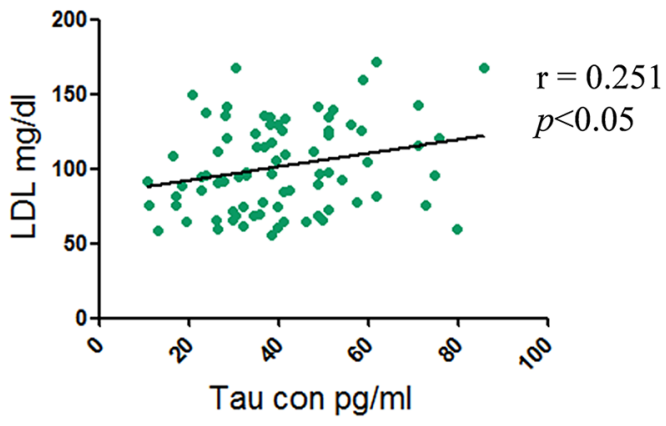

D Correlation of Copper with tau

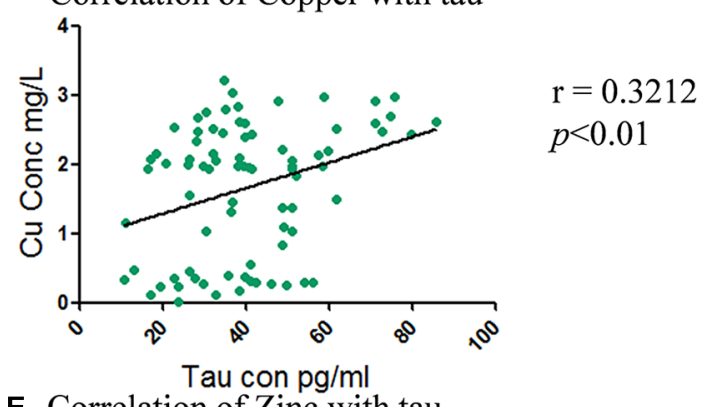

E Correlation of Zinc with tau

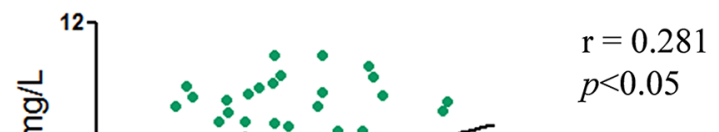

FIGURE 5 | Correlation between total and fractional serum cholesterol levels with total tau concentration and metals levels with tau. (A) Correlation of cholesterol ratio with tau. (B) Correlation of triglycerides with tau. (C) Correlation of LDL cholesterol with tau. (D) Correlation of total tau with Copper. (E) Correlation of total tau with Zinc. (F) Correlation of total tau with Aluminum.

\section{DISCUSSION}

The decline in both physical and cognitive function has been associated with increased aging. A physiological link exists between physical frailty and cognitive decline. These underlying processes include chronic inflammation, impaired hypothalamic-pituitary axis stress response, imbalanced energy metabolism, mitochondrial dysfunction, oxidative stress, and neuroendocrine dysfunction (Freitas et al., 2019; Adams et al., 2019; Yang et al., 2019; Ma and Chan, 2020). Blood-based biomarkers for CI are very important and can be effectively used to promote healthy brain aging, for screening and diagnosis at every stage of the dementias, assessment of risk to the disease, and may also be helpful in drug discovery approaches. In many cases, blood-based biomarkers lack specificity and sensitivity; hence their clinical application is limited. Tau proteins that are associated with axonal damage and amyloid proteins linked with plaque formation have been used in clinical trials as CSF based diagnostic markers for certain neurological diseases (Cummings, 2011). Interestingly, the present study showed that the concentration of both serum tau and amyloid beta- 42 were significantly different in cases of moderate and severe CI compared to mild CI and age-matched healthy controls. These findings add further evidence that serum amyloid and tau levels may improve prediction of CI, are associated with various manifestations of $\mathrm{CI}$, and may represent a useful biomarker for evaluating at-risk individuals in CI prevention trials.

A recent study reported that high levels of plasma tau was associated with a decrease in logical memory, volume of gray matter, and hippocampus (Chiu et al., 2014). Our study also showed similar results that patients of severe CI have increased levels of serum tau and tau protein levels are negatively correlated with the MMSE score. The ROC analysis 


\section{A Concentration of amyloid beta- 42 in serum samples}

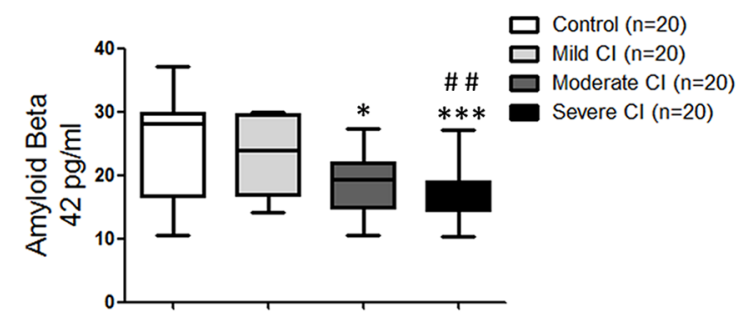

B Correlation of amyloid beta- 42 concentration with MMSE score

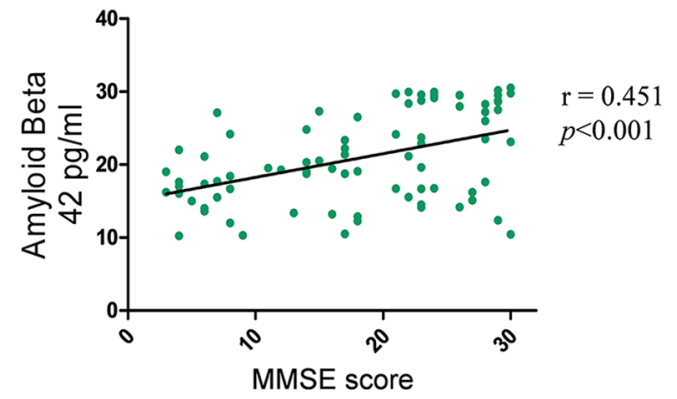

C ROC analysis for amyloid beta-42; Control vs moderate CI

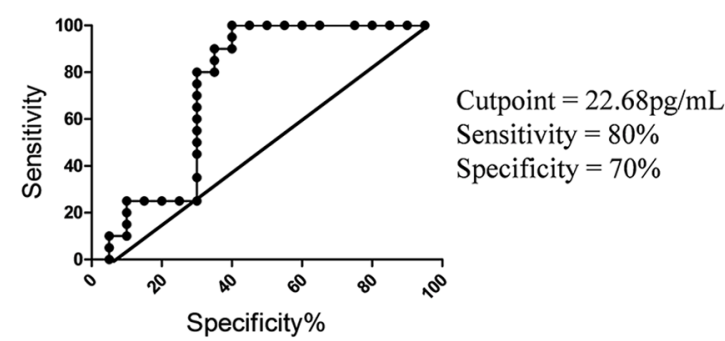

D ROC analysis for amyloid beta-42; Control vs severe CI

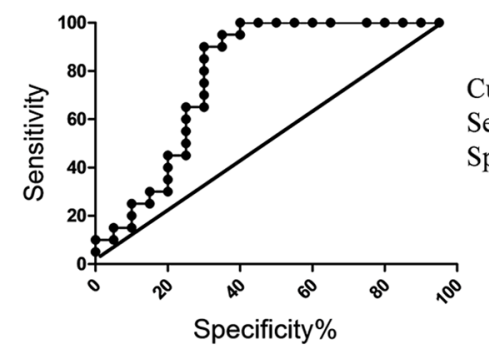

Cutpoint $=22.57 \mathrm{pg} / \mathrm{mL}$ Sensitivity $=90 \%$ Specificity $=70 \%$

FIGURE 6 | Serum amyloid beta-42 levels and its correlation with MMSE, and ROC curves. (A) Concentration of serum amyloid beta-42 in serum samples in studied subjects. ${ }^{*} p<0.05,{ }^{* * *} p<0.001$ compared with age-matched healthy control group; \#\# $p<0.01$ comparison with mild cognitive impaired group; $\mathrm{n}=$ sample size. (B) Correlation of serum amyloid beta-42 concentration with MMSE scores. ROC curves of (C) Control vs. moderate Cl and (D) Control vs. severe Cl.

determined the cutoff concentrations which were highly sensitive and specific to differentiate mild, moderate, and severe CI from age-matched healthy controls. The cutoff values from ROC analysis have depicted that tau concentration can be efficiently used to detect severe CI. Metals contribute to the pathology of CI by aggregating amyloid-beta and tau phosphorylation (Kim et al., 2018). The hyper-phosphorylation of tau leads to oxidative stress (Mandelkow and Mandelkow, 1998). $\mathrm{Cu}$ and $\mathrm{Zn}$ add to the tau pathology by directly binding with tau proteins ( $\mathrm{Ma}$ et al., 2006; Huang et al., 2014) while $\mathrm{Pb}$ and $\mathrm{Al}$ contribute to apoptosis (Zhang et al., 2012; Brown et al., 2019). Our results show that tau concentration and metals are directly correlated, where increasing metals concentration was directly affecting tau increases, and this was found in the order of $\mathrm{Cu}, \mathrm{Zn}$, and $\mathrm{Al}$, suggesting the modulatory roles of these metals.

Amyloid-beta levels are in dynamic equilibrium at the peripheral and cerebral level (Wang et al., 2006). The deposition of amyloid beta- 42 in the brain might reduce plasma levels of amyloid beta-42 (Iadecola, 2003). The accumulation of extracellular amyloid beta-42 can induce the formation of intracellular NFTs that causes organelle stress leading to neurodegeneration and $\mathrm{CI}$ in $\mathrm{AD}$. This phenomenon is termed the "snowball hypothesis" (Bi et al., 2019). The beta and gamma secretases enzyme that is involved in the amyloid beta-42 formation is dominantly localized in cholesterol-rich domains of the plasma membrane (Ehehalt et al., 2003). Studies have also shown that the cellular concentration of cholesterol might regulate the concentration and production of amyloid-beta peptides. Increased levels of cellular cholesterol shift the metabolism towards the amyloidogenic pathway however decreased cholesterol results in the non-amyloidogenic pathway (Bodovitz and Klein, 1996; Kojro et al., 2001). Different lipid-lowering therapies have been shown to interfere indirectly with amyloid-beta protofibrils by either cholesterol-dependent or cholesterol independent pathways (Shakour et al., 2019). Lipidlowering therapy has been shown to ameliorate asymptomatic intracranial atherosclerosis, which is a risk factor for vascular CI and dementia (Xie et al., 2018; Zou et al., 2018; Miao et al., 2019; Shetty et al., 2019). Atorvastatin treatment also improved cognitive outcomes and induced anti-inflammatory response in a rat model for a chronic subdural hematoma and intracerebral hemorrhage (Quan et al., 2019).

In the current study, we reported that the levels of serum amyloid-beta decreased with the progression of the disease from mild to severe. There was a positive correlation observed between levels of amyloid beta-42 and the MMSE score. The ROC cutoff value revealed that amyloid beta- 42 is more sensitive and specific to determine the different stages of disease compared to tau. The high sensitivity and specificity of serum tau and amyloid beta- 42 might be useful to diagnose the CI with high accuracy. $\mathrm{Al}, \mathrm{Cu}$, and $\mathrm{Zn}$ were found in large quantities in aggregates of amyloid beta-42 (Mantyh et al., 1993) and were strongly associated with amyloid beta- 42 levels in our study. $\mathrm{Cu}$ is required for normal brain function and $\mathrm{Cu}$ metabolism is dysregulated in brain aging (Braidy et al., 2017). Alterations in copper fluxes have also been reported in murine brain 
A Correlation of Triglycerides with amyloid beta-42

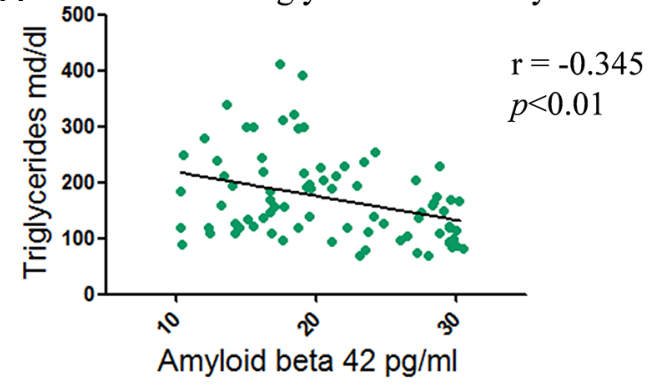

B Correlation of LDL cholesterol with amyloid beta-42

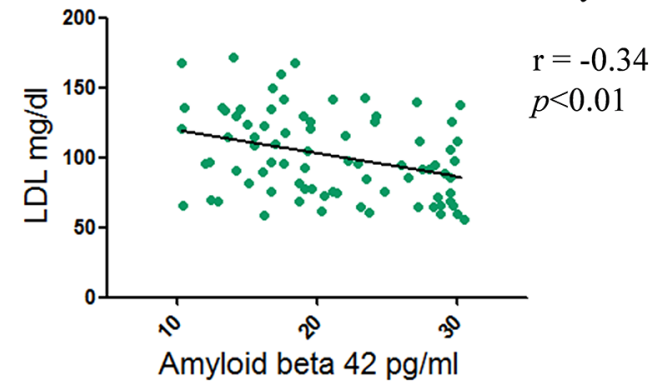

C Correlation of cholesterol ratio with amyloid beta- 42

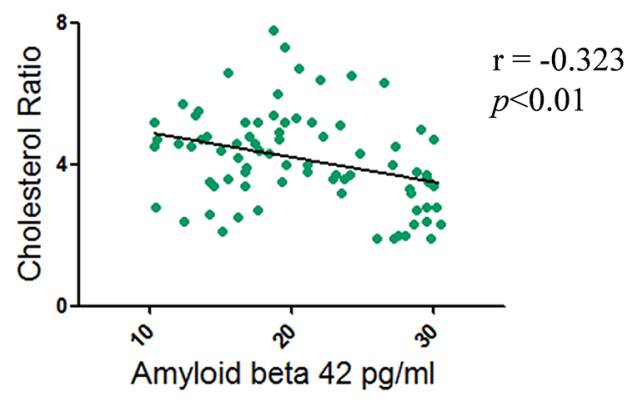

D Correlation of Zinc with amyloid beta-42

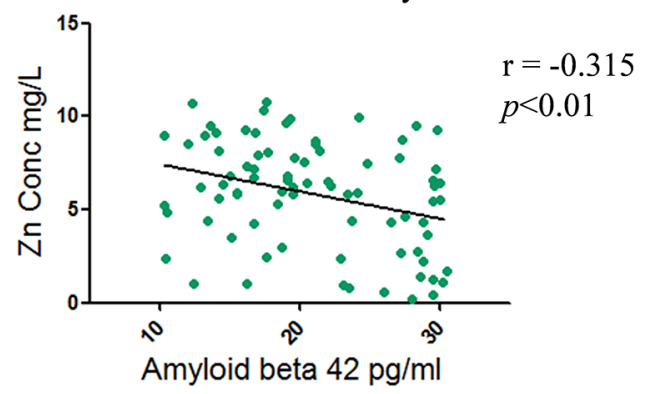

E Correlation of Lead with amyloid beta- 42

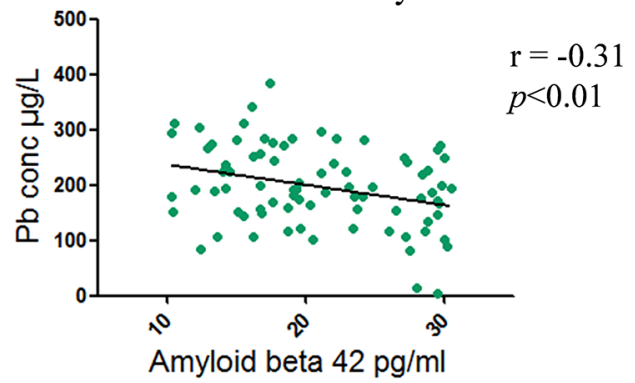

F Correlation of Copper with amyloid beta-42

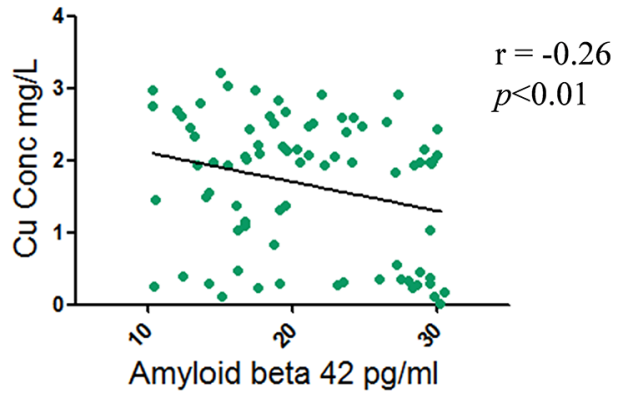

FIGURE 7 | Correlation between total and fractional serum cholesterol levels with amyloid beta-42 and metals levels with amyloid beta-42. (A) Correlation of triglycerides with amyloid beta-42. (B) Correlation of LDL cholesterol with amyloid beta-42. (C) Correlation of cholesterol ratio with amyloid beta-42. (D) Correlation of amyloid beta-42 with Zinc. (E) Correlation of amyloid beta-42 with Lead. (F) Correlation of amyloid beta-42 with Copper.

aging using ${ }^{64} \mathrm{CuCl}_{2}$ as a radiotracer $\left({ }^{64} \mathrm{CuCl}_{2}\right.$-PET/CT; Peng et al., 2018). Metals, including $\mathrm{Cu}$ and redox metals, are directly involved in the generation of amyloid plaques and indirectly by inducing oxidative stress/damage (Smith et al., 2006; Liguori et al., 2018). High Mn concentration also induces the amyloid-beta related cognitive decline in previous studies (Tong et al., 2014). Our study revealed a similar finding that metals increased the amyloid-beta aggregates and ultimately leading to decreed amyloid-beta levels in blood serum.

This study also explored the association between adverse lipid profiles and CI. We found that a low serum concentration of HDL cholesterol was linked to CI. Serum concentrations of total cholesterol, triglycerides, and LDL cholesterol showed association with CI therefore we can conclude that alteration in cholesterol metabolism in the brain might contribute to the pathology of CI. The subjects included in this study did not have cardiovascular disease or hypertension. The association of these parameters was not confounded by living standards or education status.

An association between high levels of total cholesterol, LDL cholesterol, triglycerides; and a low concentration of HDL cholesterol are risk factors for cardiovascular disease that have been previously documented (Sacco et al., 2001). Lipoproteinassociated phospholipase A2 and superoxide dismutase are linked to regulating neuroinflammation (Zhu et al., 2019). Lipoprotein cholesterol and high sensitivity C-reactive protein have also been shown to correlate with Parkinson's disease severity (Yang et al., 2020). LDL cholesterol and plasma cystatin - a protein produced by nucleated cells-has been shown to differentiate progressive supranuclear palsy from healthy subjects and predict disease severity (Weng et al., 2018). Our study reported similar results with the risk of $\mathrm{CI}$ and its propagation. In this study, HDL cholesterol was highly correlated with the CI as compared to LDL cholesterol, triglycerides, and total cholesterol. HDL cholesterol is the predominant lipoprotein 


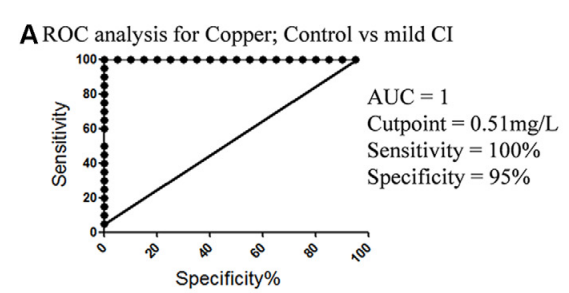

B ROC analysis for Copper; Control vs moderate CI

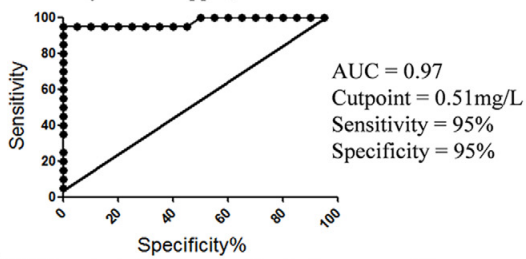

C ROC analysis for Copper; Control vs severe CI

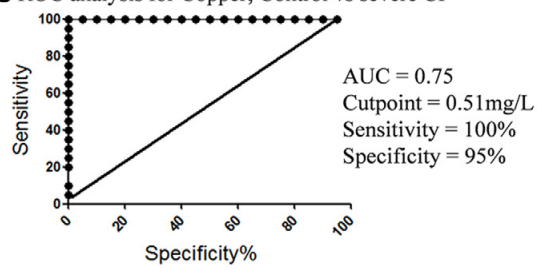

G ROC analysis for Aluminum; Control vs mild CI

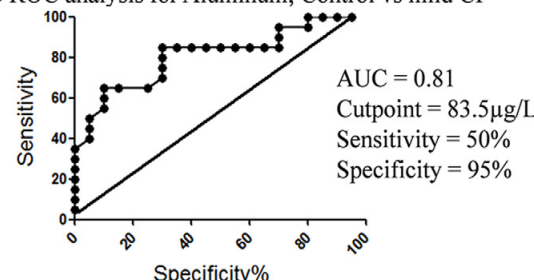

H ROC analysis for Aluminum: Control vs moderate CI

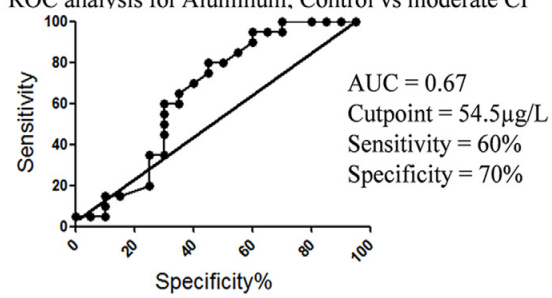

I ROC analysis for Aluminum; Control vs severe CI

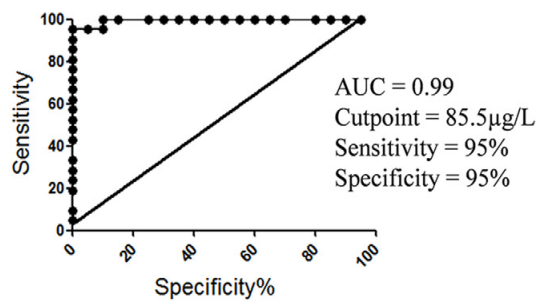

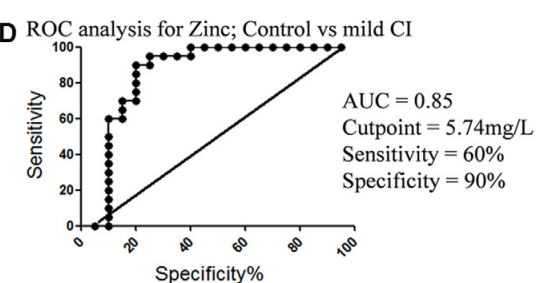

E ROC analysis for Zinc, Control vs moderate $\mathrm{CI}$

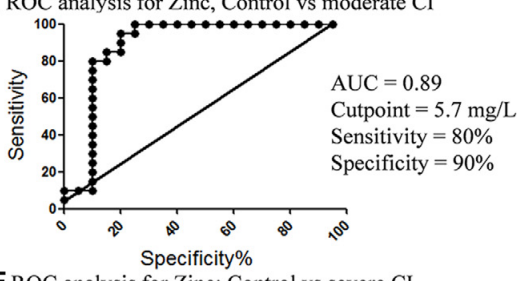

F ROC analysis for Zinc; Control vs severe $\mathrm{CI}$

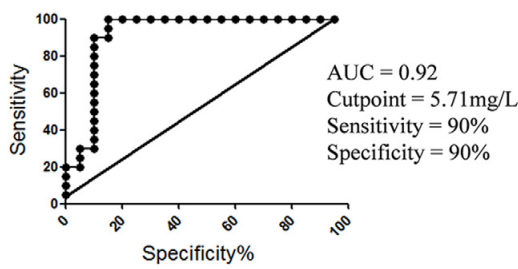

J ROC analysis for Lead; Control vs mild CI

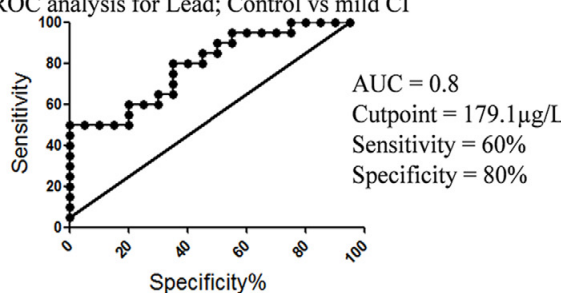

K ROC analysis for Lead; Control vs moderate CI

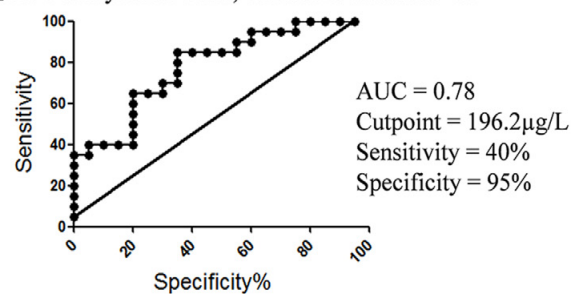

L ROC analysis for Lead; Control vs severe CI

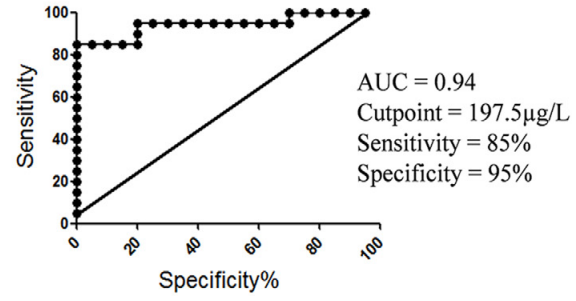

FIGURE 8 | ROC analysis of metals concentrations in different groups. (A) Copper concentration; control vs. mild Cl. (B) Copper concentration; control vs. moderate Cl. (C) Copper concentration; control vs. severe Cl. (D) Zinc concentration; control vs. mild Cl. (E) Zinc concentration; control vs. moderate Cl. (F) Zinc concentration; control vs. severe Cl. (G) Aluminum concentration; control vs. mild Cl. (H) Aluminum concentration; control vs. moderate Cl. (I) Aluminum concentration; control vs. severe Cl. (J) Lead concentration; control vs. moderate Cl. (K) Lead concentration; control vs. severe Cl. (L) Lead concentration; control vs. mild $\mathrm{Cl}$.

in the human brain (Olesen and Dagø, 2000) and prevents aggregation of amyloid proteins (Koudinov et al., 1998), and may prevent the development and progression of the disease.
The association between low levels of HDL cholesterol and progression of CI was irrespective of the presence of stroke, hypertension, and cardiovascular disease. HDL cholesterol 
has anti-inflammatory properties (Cockerill et al., 1995), and inflammation is considered to play a contributory if not causal role in neurodegenerative processes (Grundke-Iqbal et al., 1986; McGeer and McGeer, 1998).

Our study has also shown that individuals with high concentrations of LDL cholesterol were diagnosed with severe CI. The stronger correlation was demonstrated with LDL cholesterol followed by HDL cholesterol. Previous studies have also reported that individuals with $\mathrm{AD}$ have significantly higher LDL cholesterol and lower HDL cholesterol hence influencing AD pathology (Kuo et al., 1998; Moroney et al., 1999). High levels of LDL cholesterol and total cholesterol leads to microglial activation and amyloid-beta formation and may be directly involved in the pathobiology of dementia (Streit and Sparks, 1997). High serum total cholesterol may be a risk factor for CI and its progression. Total cholesterol was positively correlated with the MMSE score. One study revealed that total cholesterol is an independent risk factor for dementia and AD (Notkola et al., 1998). As well, Anstey et al showed an association between high midlife total cholesterol and cognitive decline (Anstey et al., 2008).

Triglycerides mediate CI, possibly by impairing maintenance of the $N$-methyl-D-aspartate component of hippocampal long-term potentiation and increasing oxidative stress (Razay et al., 2007; Farr et al., 2008). Our study is also consistent with previous findings, since serum triglyceride levels increased, in line with increased CI. There was a negative correlation observed between triglycerides and MMSE scores. Hence lipid-lowering therapy can improve neurological outcome (Quan et al., 2019).

This study provides insights on aging and mechanisms of CI as these are critical for novel therapies that might prevent or cure multiple age-related diseases. Among metals, $\mathrm{Cu}$ and $\mathrm{Al}$ were found to be significantly correlated with amyloid and tau. Whereas ROC analysis has also shown that $\mathrm{Cu}, \mathrm{Zn}$, and $\mathrm{Al}$ levels can be used as diagnostic markers for CI. Blood-based amyloid beta-42 and tau proteins might be used as specific biomarkers to evaluate the extent of cognitive deficits. Whereas, lipid and metal dyshomeostasis may contribute to the pathology of CI and its progression.

\section{CONCLUSION}

In conclusion, the low serum concentration of HDL cholesterol, high LDL cholesterol, total cholesterol, and triglycerides was

\section{REFERENCES}

Adams, B., Nunes, J. M., Page, M. J., Roberts, T., Carr, J., Nell, T. A., et al. (2019). Parkinson's disease: a systemic inflammatory disease accompanied by bacterial inflammagens. Front. Aging Neurosci. 11:210. doi: 10.3389/fnagi.2019. 00210

American Psychiatric Association, A. P. (1996). DSM-IV: Manual de Diagnóstico e Estatística das Perturbações Mentais. Portugal: Catalogação na publicação: Ana Paula M. Magnus CRB 10/2052.

Anstey, K. J., Lipnicki, D. M., and Low, L.-F. (2008). Cholesterol as a risk factor for dementia and cognitive decline: a systematic review of prospective studies with meta-analysis. Am. J. Geriatr. Psychiatry 16, 343-354. doi: 10.1097/JGP. 0b013e31816b72d4 associated with the progression of CI and clinical diagnosis of CI. The serum proteins, total-tau, and amyloid beta-42 may be practical to diagnose CI with high sensitivity and specificity. These findings are of clinical importance because they suggest that increasing HDL and lowering LDL cholesterol, total cholesterol, triglycerides, and metals might prevent the development and progression of CI and quantifying total-tau, $\mathrm{Cu}, \mathrm{Zn}, \mathrm{Al}$ and amyloid beta-42 may collectively represent a useful diagnostic tool.

\section{DATA AVAILABILITY STATEMENT}

All datasets generated for this study are included in the article/Supplementary Material.

\section{ETHICS STATEMENT}

The studies involving human participants were reviewed and approved by Internal Review Board (IRB) ASAB NUST. The patients/participants provided their written informed consent to participate in this study.

\section{AUTHOR CONTRIBUTIONS}

TA: project supervisor. TA, NB, and GI: study design. GI: data collection. GI: laboratory work/experimental. GI and TA: data analysis. TA, NB, and GI: manuscript preparation.

\section{ACKNOWLEDGMENTS}

We are thankful to the Atta-ur-Rahman School of Applied Biosciences, National University of Sciences and Technology, Pakistan, and the Higher Education Commission (HEC) of Pakistan for supporting this study and providing the technical research facilities. There are no financial or contractual agreements or obligations linked to the article. This research did not receive any specific grant from funding agencies in the public, commercial, or not-for-profit sectors.

\section{SUPPLEMENTARY MATERIAL}

The Supplementary Material for this article can be found online at: https://www.frontiersin.org/articles/10.3389/fnagi. 2020.00223/full\#supplementary-material.

Bi, C., Bi, S., and Li, B. (2019). Processing of mutant $\beta$-amyloid precursor protein and the clinicopathological features of familial Alzheimer's disease. Aging Dis. 10:383. doi: 10.2210/pdb1j10/pdb

Billingsley, M. L., and Kincaid, R. L. (1997). Regulated phosphorylation and dephosphorylation of tau protein: effects on microtubule interaction, intracellular trafficking and neurodegeneration. Biochem. J. 323, 577-591. doi: 10.1042/bj3230577

Bodovitz, S., and Klein, W. L. (1996). Cholesterol modulates-secretase cleavage of amyloid precursor protein. J. Biol. Chem. 271, 4436-4440. doi: 10.1074/jbc.271. 8.4436

Braidy, N., Poljak, A., Marjo, C., Rutlidge, H., Rich, A., Jugder, B.-E., et al. (2017) Identification of cerebral metal ion imbalance in the brain of aging Octodon degus. Front. Aging Neurosci. 9:66. doi: 10.3389/fnagi.2017.00066 
Brown, E. E., Shah, P., Pollock, B. G., Gerretsen, P., and Graff-Guerrero, A. (2019). Lead $(\mathrm{Pb})$ in Alzheimer's dementia: a systematic review of human case-control studies. Curr. Alzheimer Res. 16, 353-361. doi: 10.2174/1567205016666190311101445

Chen, G.-F., Xu, T.-H., Yan, Y., Zhou, Y.-R., Jiang, Y., Melcher, K., et al. (2017). Amyloid beta: structure, biology and structure-based therapeutic development. Acta Pharmacol. Sin. 38, 1205-1235. doi: 10.1038/aps. 2017.28

Chiu, M. J., Chen, Y. F., Chen, T. F., Yang, S. Y., Yang, F. P. G., Tseng, T. W., et al. (2014). Plasma tau as a window to the brain-negative associations with brain volume and memory function in mild cognitive impairment and early Alzheimer's disease. Hum. Brain Mapp. 35, 3132-3142. doi: 10.1002/hbm. 22390

Cockerill, G. W., Rye, K.-A., Gamble, J. R., Vadas, M. A., and Barter, P. J. (1995). High-density lipoproteins inhibit cytokine-induced expression of endothelial cell adhesion molecules. Arterioscler. Thromb. Vascu. Biol. 15, 1987-1994. doi: 10.1161/01.atv.15.11.1987

Cummings, J. L. (2011). Biomarkers in Alzheimer's disease drug development. Alzheimers Dement. 7, e13-e44. doi: 10.1016/j.jalz.2010.06.004

Deary, I. J., Corley, J., Gow, A. J., Harris, S. E., Houlihan, L. M., Marioni, R. E., et al. (2009). Age-associated cognitive decline. Br. Med. Bull. 92, 135-152. doi: 10.1093/bmb/ldp033

Diniz, B. S., Pinto, J. A. Jr., and Forlenza, O. V. (2008). Do CSF total tau, phosphorylated tau and $\beta$-amyloid 42 help to predict progression of mild cognitive impairment to Alzheimer's disease? A systematic review and meta-analysis of the literature. World J. Biol. Psychiatry 9, 172-182. doi: 10.1080/15622970701535502

Ehehalt, R., Keller, P., Haass, C., Thiele, C., and Simons, K. (2003). Amyloidogenic processing of the Alzheimer $\beta$-amyloid precursor protein depends on lipid rafts. J. Cell Biol. 160, 113-123. doi: 10.1083/jcb.200207113

Farr, S. A., Yamada, K. A., Butterfield, D. A., Abdul, H. M., Xu, L., Miller, N. E., et al. (2008). Obesity and hypertriglyceridemia produce cognitive impairment. Endocrinology 149, 2628-2636. doi: 10.1210/en.2007-1722

Ferrante, L. E., Murphy, T. E., Leo-Summers, L. S., Gahbauer, E. A., Pisani, M. A., and Gill, T. M. (2019). The combined effects of frailty and cognitive impairment on post-ICU disability among older ICU survivors. Am. J. Respir. Crit. Care Med. 200, 107-110. doi: 10.1164/rccm.201806-1144le

Ferrera, P., Mercado-Gómez, O., Silva-Aguilar, M., Valverde, M., and Arias, C. (2008). Cholesterol potentiates $\beta$-amyloid-induced toxicity in human neuroblastoma cells: involvement of oxidative stress. Neurochem. Res. 33, 1509-1517. doi: 10.1007/s11064-008-9623-y

Folstein, M. F., Folstein, S. E., and McHugh, P. R. (1975). "Mini-mental state": a practical method for grading the cognitive state of patients for the clinician. J. Psychiatr. Res. 12, 189-198. doi: 10.1016/0022-3956(75) 90026-6

Freedman, V. A., Aykan, H., and Martin, L. G. (2001). Aggregate changes in severe cognitive impairment among older Americans: 1993 and 1998. J. Gerontol. B Psychol. Sci. Soc. Sci. 56, S100-S111. doi: 10.1093/geronb/56.2.s100

Freitas, G. R. R., da Luz Fernandes, M., Agena, F., Jaluul, O., Silva, S. C., Lemos, F. B. C., et al. (2019). Aging and end stage renal disease cause a decrease in absolute circulating lymphocyte counts with a shift to a memory profile and diverge in treg population. Aging Dis. 10, 49-61. doi: 10.14336/ad. 2018.0318

Gandhi, S., and Abramov, A. Y. (2012). Mechanism of oxidative stress in neurodegeneration. Oxid. Med. Cell. Longev. 2012:428010. doi: $10.1155 / 2012 / 428010$

Grundke-Iqbal, I., Iqbal, K., Tung, Y.-C., Quinlan, M., Wisniewski, H. M., and Binder, L. I. (1986). Abnormal phosphorylation of the microtubule-associated protein tau (tau) in Alzheimer cytoskeletal pathology. Proc. Natl. Acad. Sci. US A 83, 4913-4917. doi: 10.1073/pnas.83.13.4913

Hansson, O., Zetterberg, H., Buchhave, P., Londos, E., Blennow, K., and Minthon, L. (2006). Association between CSF biomarkers and incipient Alzheimer's disease in patients with mild cognitive impairment: a follow-up study. Lancet Neurol. 5, 228-234. doi: 10.1016/S1474-4422(06) 70355-6

Huang, Y., Wu, Z., Cao, Y., Lang, M., Lu, B., and Zhou, B. (2014). Zinc binding directly regulates tau toxicity independent of tau hyperphosphorylation. Cell Rep. 8, 831-842. doi: 10.1016/j.celrep.2014.06.047
Iadecola, C. (2003). Cerebrovascular effects of amyloid-ßpeptides: mechanisms and implications for Alzheimer's dementia. Cell. Mol. Neurobiol. 23, 681-689. doi: 10.1023/a:1025092617651

Iqbal, G., Zada, W., Mannan, A., and Ahmed, T. (2018). Elevated heavy metals levels in cognitively impaired patients from Pakistan. Environ. Toxicol. Pharmacol. 60, 100-109. doi: 10.1016/j.etap.2018.04.011

Jia, X., Wang, Z., Yang, T., Li, Y., Gao, S., Wu, G., et al. (2019). Entorhinal cortex atrophy in early, drug-naive Parkinson's disease with mild cognitive impairment. Aging Dis. 10, 1221-1232. doi: 10.14336/AD.2018.1116

Kim, A. C., Lim, S., and Kim, Y. K. (2018). Metal ion effects on A $\beta$ and tau aggregation. Int. J. Mol. Sci. 19:128. doi: 10.3390/ijms19010128

Kojro, E., Gimpl, G., Lammich, S., März, W., and Fahrenholz, F. (2001). Low cholesterol stimulates the nonamyloidogenic pathway by its effect on the $\alpha$-secretase ADAM 10. Proc. Natl. Acad. Sci. U S A 98, 5815-5820. doi: 10.1073/pnas.081612998

Koudinov, A. R., Berezov, T. T., Kumar, A., and Koudinova, N. V. (1998). Alzheimer's amyloid $\beta$ interaction with normal human plasma high density lipoprotein: association with apolipoprotein and lipids. Clin. Chim. Acta 270, 75-84. doi: 10.1016/s0009-8981(97)00207-6

Kuo, Y.-M., Emmerling, M. R., Bisgaier, C. L., Essenburg, A. D., Lampert, H. C., Drumm, D., et al. (1998). Elevated low-density lipoprotein in Alzheimer's disease correlates with brain A $\beta$ 1-42 levels. Biochem. Biophys. Res. Commun. 252, 711-715. doi: 10.1006/bbrc.1998.9652

Liguori, I., Russo, G., Curcio, F., Bulli, G., Aran, L., Della-Morte, D., et al. (2018). Oxidative stress, aging and diseases. Clin. Interv. Aging 13, 757-772. doi: 10.2147/CIA.S158513

Liu, Y., Ky Chan, D., Thalamuthu, A., Wen, W., Jiang, J., Paradise, M., et al. (2020). Plasma lipidomic biomarker analysis reveals distinct lipid changes in vascular dementia. Comput. Struct. Biotechnol. J. 18, 1613-1624. doi: 10.1016/j. csbj.2020.06.001

Ma, L., and Chan, P. (2020). Understanding the physiological links between physical frailty and cognitive decline. Aging Dis. 11, 405-418. doi: 10.14336/ad. 2019.0521

Ma, Q., Li, Y., Du, J., Liu, H., Kanazawa, K., Nemoto, T., et al. (2006). Copper binding properties of a tau peptide associated with Alzheimer's disease studied by CD, NMR and MALDI-TOF MS. Peptides 27, 841-849. doi: 10.1016/j. peptides.2005.09.002

Mandelkow, E.-M., and Mandelkow, E. (1998). Tau in Alzheimer's disease. Trends Cell Biol. 8, 425-427. doi: 10.1016/s0962-8924(98)01368-3

Mantyh, P. W., Ghilardi, J. R., Rogers, S., DeMaster, E., Allen, C. J., Stimson, E. R., et al. (1993). Aluminum, iron and zinc ions promote aggregation of physiological concentrations of $\beta$-amyloid peptide. J. Neurochem. 61, 1171-1174. doi: 10.1111/j.1471-4159.1993.tb03639.x

Mapstone, M., Cheema, A. K., Fiandaca, M. S., Zhong, X., Mhyre, T. R., MacArthur, L. H., et al. (2014). Plasma phospholipids identify antecedent memory impairment in older adults. Nature Medicine 20, 415-418. doi: $10.1038 / \mathrm{nm} .3466$

Mattsson, N., Zetterberg, H., Hansson, O., Andreasen, N., Parnetti, L., Jonsson, M., et al. (2009). CSF biomarkers and incipient Alzheimer disease in patients with mild cognitive impairment. JAMA 302, 385-393. doi: 10.1001/jama.2009.1064

McGeer, E. G., and McGeer, P. L. (1998). The importance of inflammatory mechanisms in Alzheimer disease. Exp. Gerontol. 33, 371-378. doi: 10.1016/s0531-5565(98)00013-8

Miao, H., Yang, Y., Wang, H., Huo, L., Wang, M., Zhou, Y., et al. (2019). Intensive lipid-lowering therapy ameliorates asymptomatic intracranial atherosclerosis. Aging Dis. 10, 258-266. doi: 10.14336/ad.2018.0526

Mizoi, M., Yoshida, M., Saiki, R., Waragai, M., Uemura, K., Akatsu, H., et al. (2014). Distinction between mild cognitive impairment and Alzheimer's disease by CSF amyloid $\beta 40$ and $\beta 42$ and protein-conjugated acrolein. Clin. Chim. Acta 430, 150-155. doi: 10.1016/j.cca.2014.01.007

Monge-Argilés, J., Sanchez-Paya, J., Munoz-Ruiz, C., Pampliega-Perez, A., Montoya-Gutierrez, J., and Leiva-Santana, C. (2010). Biomarkers in the cerebrospinal fluid of patients with mild cognitive impairment: a meta-analysis of their predictive capacity for the diagnosis of Alzheimer's disease. Rev. Neurol. 50, 193-200. doi: 10.33588/rn.5004.2009163

Moroney, J. T., Tang, M.-X., Berglund, L., Small, S., Merchant, C., Bell, K., et al. (1999). Low-density lipoprotein cholesterol and the risk of dementia with stroke. JAMA 282, 254-260. doi: 10.1001/jama.282.3.254 
Nardes, F., Araújo, A. P. Q. C., Ribeiro, M. G., Bittar, M., and Gomes, H. F. (2020). The mini-mental state examination (MMSE) as a cognitive screening tool in duchenne muscular dystrophy. Ann. Child Neurol. 28, 57-65. doi: 10.26815/acn.2020.00052

Notkola, I. L., Sulkava, R., Pekkanen, J., Erkinjuntti, T., Ehnholm, C., Kivinen, P., et al. (1998). Serum total cholesterol, apolipoprotein E FC12e4 allele and Alzheimer's disease. Neuroepidemiology 17, 14-20. doi: 10.1159/000026149

Olesen, O. F., and Dagø, L. (2000). High density lipoprotein inhibits assembly of amyloid $\beta$-peptides into fibrils. Biochem. Biophys. Res. Commun. 270, 62-66. doi: 10.1006/bbrc.2000.2372

Olsson, B., Lautner, R., Andreasson, U., Öhrfelt, A., Portelius, E., Bjerke, M., et al. (2016). CSF and blood biomarkers for the diagnosis of Alzheimer's disease: a systematic review and meta-analysis. Lancet Neurol. 15, 673-684. doi: 10.1016/S1474-4422(16)00070-3

Peng, F., Xie, F., and Muzik, O. (2018). Alteration of copper fluxes in brain aging: a longitudinal study in rodent using 64CuCl2-PET/CT. Aging Dis. 9, 109-118. doi: 10.14336/ad.2017.1025

Petersen, M. E., and O'Bryant, S. E. (2019). Blood-based biomarkers for Down syndrome and Alzheimer's disease: a systematic review. Dev. Neurobiol. 79, 699-710. doi: 10.1002/dneu.22714

Postiglione, A., Cortese, C., Fischetti, A., Cicerano, U., Gnasso, A., Gallotta, G., et al. (1989). Plasma lipids and geriatric assessment in a very aged population of south Italy. Atherosclerosis 80, 63-68. doi: 10.1016/0021-9150(89) 90069-5

Quan, W., Zhang, Z., Li, P., Tian, Q., Huang, J., Qian, Y., et al. (2019). Role of regulatory $\mathrm{T}$ cells in atorvastatin induced absorption of chronic subdural hematoma in rats. Aging Dis. 10, 992-1002. doi: 10.14336/ad.2018.0926

Raz, N., and Daugherty, A. M. (2018). Pathways to brain aging and their modifiers: free-radical-induced energetic and neural decline in senescence (FRIENDS) model - a mini-review. Gerontology 64, 49-57. doi: 10.1159/0004 79508

Raz, N., and Rodrigue, K. M. (2006). Differential aging of the brain: patterns, cognitive correlates and modifiers. Neurosci. Biobehav. Rev. 30, 730-748. doi: 10.1016/j.neubiorev.2006.07.001

Raz, N., Rodrigue, K. M., Head, D., Kennedy, K. M., and Acker, J. D. (2004). Differential aging of the medial temporal lobe. Neurology 62, 433-438. doi: 10.1212/01.wnl.0000106466.09835.46

Razay, G., Vreugdenhil, A., and Wilcock, G. (2007). The metabolic syndrome and Alzheimer disease. Arch. Neurol. 64, 93-96. doi: 10.1001/archneur.64.1.93

Ritchie, C., Smailagic, N., Noel-Storr, A. H., Takwoingi, Y., Flicker, L., Mason, S. E., et al. (2014). Plasma and cerebrospinal fluid amyloid beta for the diagnosis of Alzheimer's disease dementia and other dementias in people with mild cognitive impairment (MCI). Cochrane Database Syst. Rev. 6:CD008782. doi: 10.1002/14651858.cd008782.pub4

Ritchie, C., Smailagic, N., Noel-Storr, A. H., Ukoumunne, O., Ladds, E. C., and Martin, S. (2017). CSF tau and the CSF tau/A $\beta$ ratio for the diagnosis of Alzheimer's disease dementia and other dementias in people with mild cognitive impairment (MCI). Cochrane Database Syst. Rev. 3:CD010803. doi: 10.1002/14651858.cd010803.pub2

Ruiz, A., Pesini, P., Espinosa, A., Pérez-Grijalba, V., Valero, S., SotolongoGrau, O., et al. (2013). Blood amyloid beta levels in healthy, mild cognitive impairment and Alzheimer's disease individuals: replication of diastolic blood pressure correlations and analysis of critical Covariates. PLoS One 8:e81334. doi: 10.1371/journal.pone.0081334

Sacco, R. L., Benson, R. T., Kargman, D. E., Boden-Albala, B., Tuck, C., Lin, I.F., et al. (2001). High-density lipoprotein cholesterol and ischemic stroke in the elderly: the Northern Manhattan Stroke Study. JAMA 285, 2729-2735. doi: 10.1001/jama.285.21.2729

Segatto, M., Leboffe, L., Trapani, L., and Pallottini, V. (2014). Cholesterol homeostasis failure in the brain: implications for synaptic dysfunction and cognitive decline. Curr. Med. Chem. 21, 2788-2802. doi: 10.2174/0929867321666140303142902

Selkoe, D. J. (1994). Normal and abnormal biology of the beta-amyloid precursor protein. Annu. Rev. Neurosci. 17, 489-517. doi: 10.1146/annurev.ne.17.030194. 002421

Shakour, N., Bianconi, V., Pirro, M., Barreto, G. E., Hadizadeh, F., and Sahebkar, A. (2019). In silico evidence of direct interaction between statins and $\beta$-amyloid. J. Cell. Biochem. 120, 4710-4715. doi: 10.1002/jcb. 27761

Shetty, A. K., Upadhya, R., Madhu, L. N., and Kodali, M. (2019). Novel insights on systemic and brain aging, stroke, amyotrophic lateral sclerosis, and Alzheimer's disease. Aging Dis. 10, 470-482. doi: 10.14336/ad.2019.0330

Singh, A., Kukreti, R., Saso, L., and Kukreti, S. (2019). Oxidative stress: a key modulator in neurodegenerative diseases. Molecules 24:1583. doi: 10.3390/molecules24081583

Smith, D. P., Smith, D. G., Curtain, C. C., Boas, J. F., Pilbrow, J. R., Ciccotosto, G. D., et al. (2006). Copper-mediated amyloid- $\beta$ toxicity is associated with an intermolecular histidine bridge. J. Biol. Chem. 281, 15145-15154. doi: 10.1074/jbc.M600417200

Song, F., Poljak, A., Valenzuela, M., Mayeux, R., Smythe, G. A., and Sachdev, P. S. (2011). Meta-analysis of plasma amyloid- $\beta$ levels in Alzheimer's disease. J. Alzheimers Dis. 26, 365-375. doi: 10.3233/JAD-2011101977

Sparks, D. L., Scheff, S. W., Hunsaker, J. C. III., Liu, H., Landers, T., and Gross, D. R. (1994). Induction of Alzheimer-like $\beta$-amyloid immunoreactivity in the brains of rabbits with dietary cholesterol. Exp. Neurol. 126, 88-94. doi: 10.1006/exnr.1994.1044

Streit, W., and Sparks, D. L. (1997). Activation of microglia in the brains of humans with heart disease and hypercholesterolemic rabbits. J. Mol. Med. 75, 130-138. doi: 10.1007/s001090050097

Tang, W., Wang, Y., Cheng, J., Yao, J., Yao, Y.-Y., Zhou, Q., et al. (2020). CSF sAPP $\alpha$ and sAPP $\beta$ levels in Alzheimer's disease and multiple other neurodegenerative diseases: a network meta-analysis. Neuromolecular Med. 22, 45-55. doi: 10.1007/s12017-019-08561-7

Tong, Y., Yang, H., Tian, X., Wang, H., Zhou, T., Zhang, S., et al. (2014). High manganese, a risk for Alzheimer's disease: high manganese induces amyloid- $\beta$ related cognitive impairment. J. Alzheimers Dis. 42, 865-878. doi: 10.3233/jad140534

Vos, S. J. B., van Rossum, I. A., Verhey, F., Knol, D. L., Soininen, H. and Wahlund, L.-O.. (2013). Prediction of Alzheimer Disease in subjects with amnestic and nonamnestic MCI. Neurology 80, 1124-1132. doi: 10.1212/WNL.0b013e318288690c

Wang, Y.-J., Zhou, H.-D., and Zhou, X.-F. (2006). Clearance of amyloid-beta in Alzheimer's disease: progress, problems and perspectives. Drug Discov. Today 11, 931-938. doi: 10.1016/j.drudis.2006.08.004

Weng, R., Wei, X., Yu, B., Zhu, S., Yang, X., Xie, F., et al. (2018). Combined measurement of plasma cystatin $\mathrm{C}$ and low-density lipoprotein cholesterol: a valuable tool for evaluating progressive supranuclear palsy. Parkinsonism Relat. Disord. 52, 37-42. doi: 10.1016/j.parkreldis.2018.03.014

Wieringa, G. E., Burlinson, S., Rafferty, J. A., Gowland, E., and Burns, A. (1997). Apolipoprotein E genotypes and serum lipid levels in Alzheimer's disease and multi-infarct dementia. Int. J. Geriatr. Psychiatry 12, 359-362. doi: 10.1002/(sici)1099-1166(199703)12:3<359::aid-gps506> 3.0.co; $2-\mathrm{x}$

Xicoy, H., Wieringa, B., and Martens, G. J. (2019). The role of lipids in Parkinson's disease. Cells 8:27. doi: 10.3390/cells8010027

Xie, F., Gao, X., Yang, W., Chang, Z., Yang, X., Wei, X., et al. (2018). Advances in the research of risk factors and prodromal biomarkers of Parkinson's disease. ACS Chem. Neurosci. 10, 973-990. doi: 10.1021/acschemneuro.8b 00520

Yang, Q., Huang, Z., Luo, Y., Zheng, F., Hu, Y., Liu, H., et al. (2019). Inhibition of $\mathrm{Nwd} 1$ activity attenuates neuronal hyperexcitability and GluN2B phosphorylation in the hippocampus. EBioMedicine 47, 470-483. doi: 10.1016/j.ebiom.2019.08.050

Yang, W., Chang, Z., Que, R., Weng, G., Deng, B., Wang, T., et al. (2020). Contra-directional expression of plasma superoxide dismutase with lipoprotein cholesterol and high-sensitivity c-reactive protein as important markers of Parkinson's disease severity. Front. Aging Neurosci. 12:53. doi: 10.3389/fnagi. 2020.00053

Zanchetti, A., Liu, L., Mancia, G., Parati, G., Grassi, G., Stramba-Badiale, M., et al. (2014). Blood pressure and low-density lipoprotein-cholesterol lowering for prevention of strokes and cognitive decline: a review of available trial evidence. J. Hypertens. 32, 1741-1750. doi: 10.1097/HJH.00000000000 00253 
Zetterberg, H., Wilson, D., Andreasson, U., Minthon, L., Blennow, K., Randall, J., et al. (2013). Plasma tau levels in Alzheimer's disease. Alzheimers Res. Ther. 5:9. doi: 10.1186/alzrt163

Zhang, J., Cai, T., Zhao, F., Yao, T., Chen, Y., Liu, X., et al. (2012). The role of $\alpha$-synuclein and tau hyperphosphorylation-mediated autophagy and apoptosis in lead-induced learning and memory injury. Int. J. Biol. Sci. 8, 935-944. doi: 10.7150/ijbs.4499

Zhu, S., Wei, X., Yang, X., Huang, Z., Chang, Z., Xie, F., et al. (2019). Plasma lipoprotein-associated phospholipase A2 and superoxide dismutase are independent predicators of cognitive impairment in cerebral small vessel disease patients: diagnosis and assessment. Aging Dis. 10, 834-846. doi: 10.14336/AD.2019.0304

Zou, J., Chen, Z., Liang, C., Fu, Y., Wei, X., Lu, J., et al. (2018). Trefoil factor 3, cholinesterase and homocysteine: potential predictors for Parkinson's disease dementia and vascular parkinsonism dementia in advanced stage. Aging Dis. 9 51-65. doi: 10.14336/ad.2017.0416

Conflict of Interest: The authors declare that the research was conducted in the absence of any commercial or financial relationships that could be construed as a potential conflict of interest.

Copyright (C) 2020 Iqbal, Braidy and Ahmed. This is an open-access article distributed under the terms of the Creative Commons Attribution License (CC BY). The use, distribution or reproduction in other forums is permitted, provided the original author(s) and the copyright owner(s) are credited and that the original publication in this journal is cited, in accordance with accepted academic practice. No use, distribution or reproduction is permitted which does not comply with these terms. 